\title{
Phosphorus and Arsenic Diffusions from Doped Polycrystalline Silicon
}

\author{
Yasutaka IKUSHIMA* and Mototaka KAMOSHIDA*
}

\begin{abstract}
Diffusions from phosphorus and arsenic doped polycrystalline silicon iato crystalline silicon substrate have been investigated. Phosphorus profiles reveal two regions with different diffusion coefficients, i.e. $1.2 \times 10^{-14}$ and $6.0 \times 10^{-14} \mathrm{~cm}^{2} / \mathrm{sec}$, that are almost similar to the values of doped oxide-diffusion obtained by Yoshida and conventional gas phase -diffusion by Tsai. The total arsenic concentration profile determined from electrically measured profile by means of Fair's method shows a good agreement with that obtained from doped oxide by Fair. No remarkable difference was recognized between profiles of diffusions in dry oxygen and nitrogen.
\end{abstract}

\section{Introduction}

In fabricating micro-wave transistors and integrated circuits using conventional planar techniques, it is required that the junction depth should be shallow such as $\sim 0.2 \mu$ depth of an emitter junction in order to improve the frequency characteristics. After the metallization of an aluminum electrode, however, an emitter-base short occurs very often because of such short distance between the junction and the aluminum electrode. Recently, Kamioka et al. ${ }^{1)}$ have shown that shallow pn junction can be formed by diffu. sion from impurity-doped polycrystalline silicon doposited on single crystalline silicon substrate. Such Doped Poly Silicon technique (DOPOS) is very useful to prevent the above mentioned failure due to the existence of deposited polysilicon between the pn junction and the aluminum electrode. Although the diffusion from a doped oxide has been studied by several workers $^{2) \sim 6}$, few studies ${ }^{7)}$ have been reported on diffusion from a doped poly-silicon.

This paper reports the study of diffusion characteristics from dopef poly-silicon, such as concentration profile, junction depth and sheet resistivity. Phosphorus and arsenic diffusion coefficients are determined by Boltzmann-Matano

* IC Division, Nippon Electric Company, Limited (1753 Shimonumabe, Nakahara-ku, Kawasaki) analysis $^{8)}$ and the concentration dependence of the diffusion coefficient is compared with that obtained by other investigators ${ }^{3)-11}$.

\section{Experimental Procedures}

As the starting material, boron doped $1 \Omega-\mathrm{cm}$ $p$-Si (111) wafers were mechanically and chemically polished and cleaned. The cleaning procedure involved rinsing in trichloroethylene and acetone and boiling in nitric acid and sulfuric acid. Immediately prior to the deposition of poly-silicon, the silicon wafers were dipped into an $\mathrm{HF}$ solution to remove a very thin silicon oxide layer.

The poly-silicon films were deposited in an rf induction-heated reactor. Phosphorus and arsenic doped poly-silicon was deposited on the silicon wafers from $\mathrm{SiH}_{4}-\mathrm{PH}_{3}-\mathrm{N}_{2}$ and $\mathrm{SiH}_{4}$ $\mathrm{AsCl}_{3}-\mathrm{N}_{2}$ mixtures at $690^{\circ} \mathrm{C}$ and $750^{\circ} \mathrm{C}$, respectively. The temperature of the silicon wafers was measured with an infrared scope. In this experiment, phosphorus-doped poly-silicon films ranging from 500 to $4000 \AA$ thick and arsenic doped poly-silicon films of $2500 \AA$ thick were deposited. Other experimental deposition conditions are listed on Table 1. Pefore drive-in diffusion, phosphorus-doped poly-silicon films were coated with $5000 \AA$ thick $\mathrm{CVD} \mathrm{SiO}_{z}$ films to prevent out-diffusion. Phosphorus and 
Table 1 Typical doped poly-silicon growth conditions

\begin{tabular}{l|c|c}
\hline & P dope & As dope \\
\hline $\mathrm{SiH}_{4}$ (cc/min.) & 15 & 3 \\
$\mathrm{PH}_{3}$ (cc/min.) & 0.4 & - \\
$\mathrm{N}_{2}$ (AsCl ${ }_{3}$ bubble) (cc/min.) & - & $20\left(10^{\circ} \mathrm{C}\right)$ \\
$\mathrm{N}_{2}$ (carrier) $(l / \mathrm{min})$. & 30 & 3 \\
Growth Temperature $\left({ }^{\circ} \mathrm{C}\right)$ & 690 & 750 \\
Growth Rate $(\AA /$ min. $)$ & 160 & 400 \\
Reactor & horizontal & vertical \\
\hline
\end{tabular}

arsenic drive-in diffusions from doped polysilicon films were carried out at $900^{\circ} \mathrm{C}$ and at $1000 \sim 1100^{\circ} \mathrm{C}$, respectively, in dry nitrogen or oxygen atmosphere.

To determine the poly-silicon thickness and the interface between doped poly-silicon and the substrate ${ }^{12}$, the doped poly-silicon was also deposited onto silicon wafers partially covered with thermally grown silicon oxide of $2000 \AA$ thick. When the structure was immersed into an etch mixture containing 1 part $\mathrm{HF}$ (49\%), 20 parts $\mathrm{HNO}_{3}(70 \%)$ and 20 parts $\mathrm{CH}_{3} \mathrm{COOH}$ (99.9\%) at room temperature, the doped polysilicon etch rate was $80 \sim 120 \AA /$ sec while the silicon oxide etch rate was $3.5 \AA / \mathrm{sec}$. Even after the drive-in diffusion above $900^{\circ} \mathrm{C}$, the etch rate of the phosphorus doped and arsenic doped poly-silicon films was $60 \sim 80 \AA / \mathrm{sec}$, while that of the single crystal silicon wafer with 1 $\Omega-\mathrm{cm}$ resistivity was $30 \sim 40 \AA \mathrm{A} / \mathrm{sec}$. The etching end-point of poly-silicon on silicon dioxide could indicate the substrate-poly-silicon interface within the errors of $\pm 150 \AA$. The poly-silicon thickness was also confirmed with a Taylor Hobson Talystep.

To obtain the impurity profile, a layer removal technique was carried out in a mixture containing 1 part $\mathrm{HF}$ (49\%) and 30 parts $\mathrm{CuSO}_{4}$ solution $\left(120 \mathrm{~g} \mathrm{CuSO}_{4}\right.$ in $1000 \mathrm{cc}$ water). Since the resistivity of each layer was given by

$$
\frac{d\left(\rho_{\mathrm{s}}{ }^{-1}\right)}{d x}=-\frac{1}{\rho}
$$

where $\rho_{\mathbf{s}}$ is the measured sheet resistivity, $x$ is the layer thickness.

Phosphorus and arsenic concentration profiles were obtained from Irvin's curves concerning impurity concentration $v s$, resistivity. ${ }^{13)}$ In the doped poly-silicon, the concentrations of the phosphorus and arsenic were $4 \sim 6 \times 10^{19}$ atoms/ $\mathrm{cm}^{3}$ without a correction which took into account the smaller electron mobility in the doped polysilicon than that in the single crystal silicon ${ }^{14}$. At the surface of the single silicon wafer, the concentration increased rapidly more than $1 \times 10^{20}$ atoms $/ \mathrm{cm}^{3}$. Therefore, the interface between the doped poly-silicon and the single crystal silicon wafer could be determined electrically. The junction depths obtained with the angle lapping and staining agreed with those determined from the concentration profiles within the error of $10 \%$.

\section{Results and Discussion}

\subsection{Phosphorus diffusion}

3.1.1 Phosphorus concentration profiles

Phosphorus concentration profiles, obtained with diffusions at $900^{\circ} \mathrm{C}$ for 29,100 and 225 minutes, are shown in Fig. $1 \mathrm{~A}, \mathrm{~B}$ and $\mathrm{C}$, respectively, There are two regions in each profile. One is near the surface (region I), where the concentration decreases rapidly, i.e. the diffusion coefficient $D_{\mathrm{I}}$ is small. The other is far from the surface (region II), where the concentration decreases slowly, i.e. diffusion coefficient $D_{\text {II }}$ is larger than $D_{\mathrm{I}}$. These two regions exist in cases of both 500 and $2000 \AA$ thick films. The existence of two regions in the phosphorus profile has also been reportet by Yoshida et $a l^{109}$., who carried out phosphorus diffusions from the phosphorus-doped-oxide. In the case of conventional diffusion from $\mathrm{P}_{2} \mathrm{O}_{5}$ or $\mathrm{POCl}_{3}$, Tannenbaum ${ }^{15)}$, Duffy et al. $^{16)}$ and Tsai $^{9)}$ have also shown that a very high constant concentration region exists on the surface of the phosphorusdiffused layer. Such a flat region could not be observed in this doped poly-silicon case. Tsai ${ }^{9}$ ' indicated that diffusion coefficient difference was attributed to the diffusions of the silicon phosphide and of phosphorus. Yoshida et $a l{ }^{10)}$ concluded that, in the doped oxide case, the phosphorus diffusion coefficient was dependent on both concentration and surface condition.

It has been reported ") that the high concentration phosphorus diffusion into silicon induces the dislocations. The dislocations are not desirable for the semiconductor device fabrications 


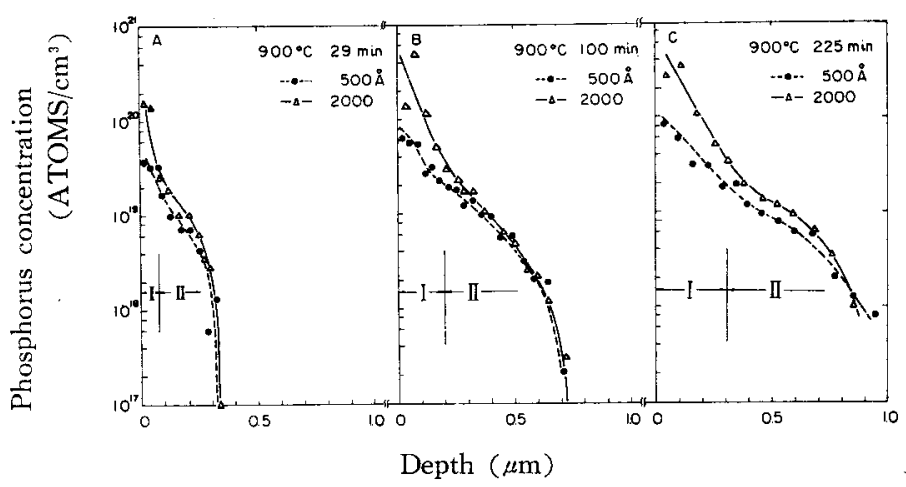

Fig. 1 Phosphorus concentration profiles obtained with diffusion from doped poly-silicon of $500 \AA$ thick (O) and $2000 \AA$ thick $(\triangle)$

(A) $900^{\circ} \mathrm{C} .29$ minutes, (B) $900^{\circ} \mathrm{C}, 100$ minutes and (C) $900^{\circ} \mathrm{C}, 225$ minutes in $\mathrm{N}_{2}$

${ }^{16)}$. In the present diffusion process, the phosphorus diffused layers did not cause dislocation arrays, which is confirmed by Sirtl etch technique.

3.1.2 Film thickness effects As shown in Fig. 1, the junction depth does not depend on film thickness within this experimental range. Figure 2 shows the relation between junction depth and diffusion time for various film thick. nesses, indicating that the junction depth is approximately proportional to the square root of diffusion time.

Figure 1 also indicates that, at region $I$, the phosphorus concentration diffused from a $500 \AA$ poly-silicon film is lower than that from a 2000

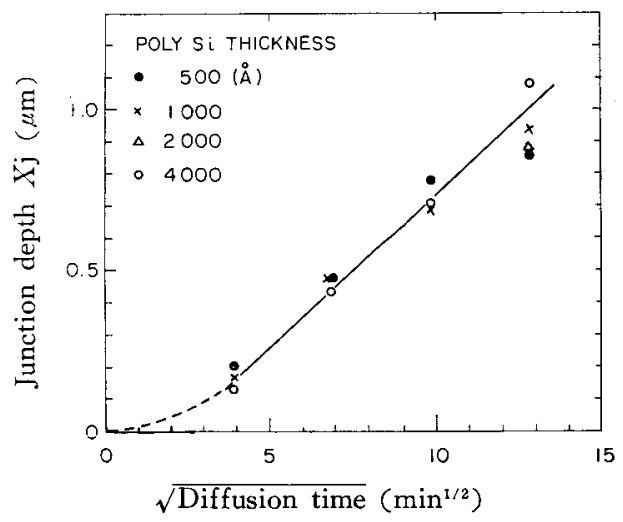

Fig. 2 Junction depth obtained with diffusion from phosphorus doped poly-silicon at $900^{\circ} \mathrm{C}$ vs. square root of diffusion time

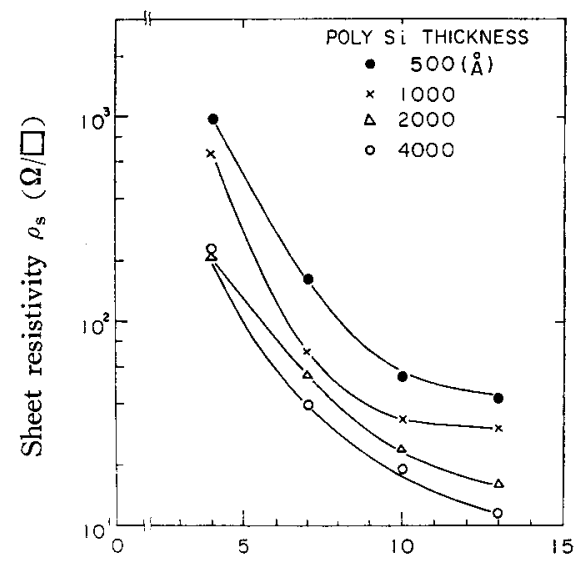

$\sqrt{\text { Diffusion time }}\left(\min ^{1 / 2}\right)$

Fig, 3 Sheet resistivity obtained with diffusion from phosphorus doped poly-silicon at $900^{\circ} \mathrm{C} v s$. square root of diffusion time. Polysilicon thicknesses are given as parameters

$\AA$ film. It suggests that sheet resistivity of diffused silicon surface depends on the source film thickness. Figure 3 shows the relations between sheet resistivity and diffusion time. Sheet resistivity decreases with film thickness increasing, corresponding to Fig. 1. Yasuda et al. ${ }^{18}$ ) have also confirmed that the boron concentration in the doped poly-silicon with the film thickness below $1000 \AA$ lwas ower than that of a film thickness above $1000 \AA$. The concentration difference at region $\mathrm{I}$ also corresponds to this phenomenon. 
As shown in Fig. 3, the sheet resistivities of diffused layers from $500 \AA$ and $1000 \AA$ films begin to saturate as the diffusion time becomes longer than 100 minutes. However, sheet resistivities obtained with $2000 \AA$ and $4000 \AA$ films do not saturate even for 169 minutes diffusion. This means that, in the case of film thickness greater than $2000 \AA$, the diffusion source has sufficient amounts of phosphorus for a long diffusion time of at least up to 169 minutes.

\subsubsection{Phosphorus diffusion coefficient}

As described in Sec. 3.1.1, the phosphorus diffusion coefficient depends on the concentration. Thus, Boltzmann-Matano analysis ${ }^{83}$ was used to determine the diffusion coefficient, that is, the diffusion coefficient is represented by

$$
D(n)=-\frac{1}{2 t} \frac{d x}{d n} \int_{n(x=\infty)}^{n(x)} x d n
$$

where $D$ is the diffusion coefficient and $t$ is the diffusion time. Here, as explained by Yoshida et $a l .{ }^{102}$, it is also confirmed that the concentration is a function of $x / \sqrt{t}$.

Figure 4 shows the phosphorus diffusion coefficients determined from Eq. (2) using the profiles of $2000 \AA$ poly-silicon film indicated in Fig. 1. In the region of a concentration lower than $10^{19} \mathrm{~cm}^{-3}$, the diffusion coefficient was given as a large value $\left(D_{\mathbb{I}} \cong 6 \times 10^{-14} \mathrm{~cm}^{2} / \mathrm{sec}\right)$, while in higher concentration of $\sim 10^{20} \mathrm{~cm}^{-3}$, it decreased and reached a small value $\left(D_{\mathrm{I}} \cong 1.2 \times 10^{-14}\right.$ $\mathrm{cm}^{2} / \mathrm{sec}$ ). This tendency coincides qualitatively with Tsai's ${ }^{9)}$ and Yoshida et $a l^{\prime} \mathrm{s}^{10)}$ results.

Tsai has suggested quantitatively that the phosphorus diffusion profiles were derived from

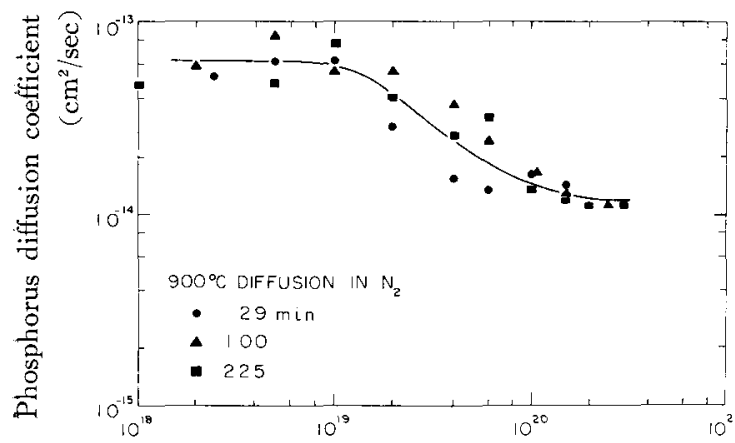

Phosphorus concentration (atoms $/ \mathrm{cm}^{3}$ )

Fig. 4 Dependence of phosphorus diffusion coefficient on phosphorus concentration in $2000 \AA$ poly-silicon film
Fick's diffusion equations using a model where a moving boundary separates two distinct phases, and has determined the small and large coefficents, as $2.7 \times 10^{-15} \mathrm{~cm}^{2} / \mathrm{sec}$ and $5.7 \times 10^{-14}$ $\mathrm{cm}^{2} / \mathrm{sec}$. Although a good agreement was obtained between this doped poly-silicon case and conventional gas phase diffusion case in a large coefficient region, a slight difference was observed in a small coefficient region.

\subsection{Arsenic diffusion}

\subsubsection{Arsenic concentration profiles}

Figure $5 \mathrm{~A}, \mathrm{~B}, \mathrm{C}$ and $\mathrm{D}$ shows arsenic concentration profiles obtained with the diffusion from the $2500 \AA$ arsenic-doped poly-silicon films with various gas phase-molar ratios of $\mathrm{AsCl}_{3}$ / $\mathrm{SiH}_{4}$. Concentration gradients are small in the high concentration region $\left(\geqq 1 \times 10^{20} \mathrm{~cm}^{-3}\right)$ and increase rapidly near the junction. These phenomena are similar to those found in the studies reported by many workers. ${ }^{1,41,3), 11,193,20)}$ In adcreases near dition, the concentration slightly dethe surface at $\mathrm{AsCl}_{3} / \mathrm{SiH}_{4}$ of $7 \times 10^{-2}$, as reported by $\mathrm{Fair}^{20}$. In the case of $0.7 \times 10^{-2} \mathrm{AsCl}_{3} / \mathrm{SiH}_{4}$ ratio, the arsenic concentration is lower than that

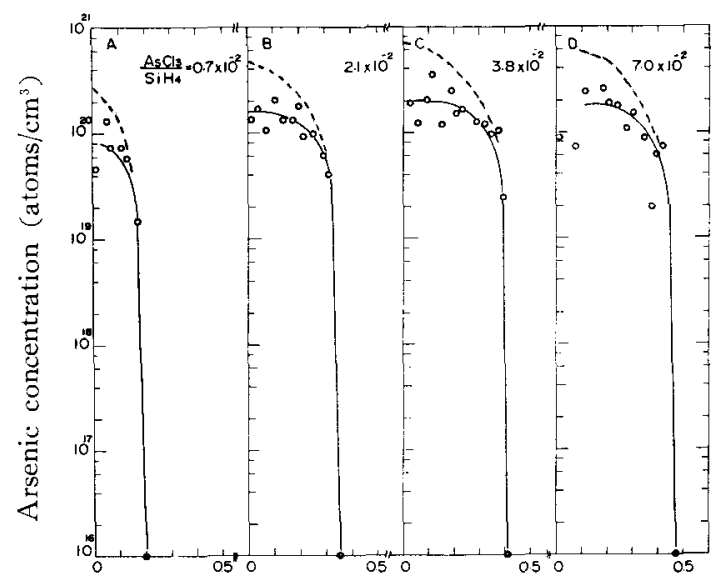

Depth $(\mu \mathrm{m})$

Fig. 5 Arsenic concentration profiles obtained with diffusion at $1000^{\circ} \mathrm{C}$ for 60 minutes in $\mathrm{O}_{2}$ on molar ratios of $\mathrm{AsCl}_{3} / \mathrm{SiH}_{4}$. Dotted lines indicate total arsenic concentration profiles calculated by Fair's method

(A) $\mathrm{AsCl}_{3} / \mathrm{SiH}_{4}=0.7 \times 10^{-2}$, (B) 2.1 $\times 10^{-2}$, (C) $3.8 \times 10^{-2}$ and (D) 7.0 $\times 10^{-2}$ 
from the others and the junction depth is also shallower than that from the others. On the other hand, arsenic concentration profiles obtained with diffusion at $1000^{\circ} \mathrm{C}$ for 60 minutes from the arsenic-doped poly-silicon films with 1000, 2000, and $4000 \AA$ thicknesses agree with one another.

3.2.2 Molar ratio $\left(\mathrm{AsCl}_{3} / \mathrm{SiH}_{4}\right)$ dependence Figure 6 shows the sheet resistivity and the junction depth obtained with the diffusion from the $2500 \AA$ doped poly-silicon for various molar ratios of $\mathrm{AsCl}_{3} / \mathrm{SiH}_{4}$. In the case of $\mathrm{AsCl}_{3} / \mathrm{SiH}_{4}$ of 0.7 $\times 10^{-2}$, the sheet resistivity is higher, which corresponds to the shallower junction depth. The sheet resistivity decreases as the ratio of $\mathrm{AsCl}_{3}$ / $\mathrm{SiH}_{4}$ increases and it begins to saturate above $3.8 \times 10^{-2}$. On the contrary the junction depth increases and saturates as the ratio of $\mathrm{AsCl}_{3} / \mathrm{SiH}_{4}$ increases. These facts are consistent with the profiles in Fig. $5 \mathrm{~A}, \mathrm{~B}, \mathrm{C}$ and $\mathrm{D}$.

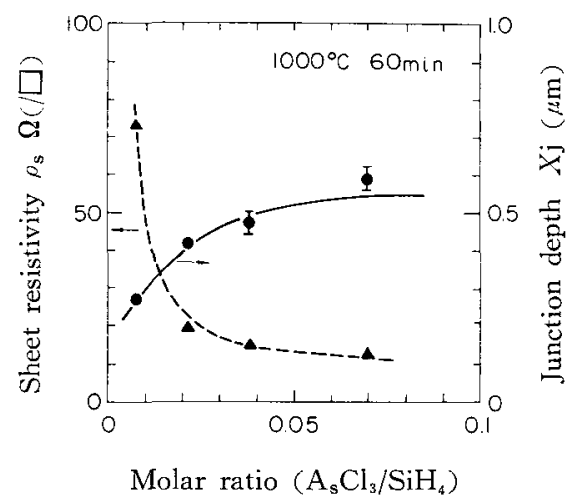

Fig. 6 Molar ratio $\left(\mathrm{AsCl}_{3} / \mathrm{SiH}_{4}\right)$ dependence of sheet resistivity and junction depth obtained with diffusion at $1000^{\circ} \mathrm{C}$ for 60 minutes

Fair $^{21}$ showed that, for a constant $C_{\mathrm{S}}$ diffusion,

$$
C_{\mathrm{S}}=\frac{1.56 \times 10^{17}}{\rho_{\mathbf{s}} x_{\mathbf{j}}} \quad\left(\text { atoms } / \mathrm{cm}^{3}\right)
$$

where $C_{\mathrm{S}}$ is the electrically active surface concentration. Equation (3) is always valid in dependent of the type of arsenic diffusion ${ }^{21}$. Then the surface concentrations of electrically active arsenic, $C_{\mathrm{AO}}$, are calculated for the various molar ratios of $\mathrm{AsCl}_{3} / \mathrm{SiH}_{4}$ by using $\rho_{\mathbf{s}}$ and $x_{\mathbf{j}}$ shown in Fig. 6. Calculated $C_{\mathrm{AO}}$ values are $8.3 \times 10^{19}$ atoms $/ \mathrm{cm}^{3}$ for $\mathrm{AsCl}_{3} / \mathrm{SiH}_{4}=0.7 \times 10^{-2}, 1.9 \times 10^{20}$ atoms $/ \mathrm{cm}^{3}$ for $\mathrm{AsCl}_{3} / \mathrm{SiH}_{4}=2.1 \times 10^{-2}, 2.2 \times 10^{20}$ atoms $/ \mathrm{cm}^{3}$ for $\mathrm{AsCl}_{3} / \mathrm{SiH}_{4}=3.8 \times 10^{-2}$ and $2.2 \times$
$10^{20}$ atoms $/ \mathrm{cm}^{3}$ for $\mathrm{AsCl}_{3} / \mathrm{SiH}_{4}=7.0 \times 10^{-2}$, respectively. These calculated $C_{\mathrm{AO}}$ values are coincident with those shown in Fig. 5 within the limit of errors of $10 \sim 15 \%$, except for the case of $\mathrm{AsCl}_{3} / \mathrm{SiH}_{4}=7.0 \times 10^{-2}$. Therefore, it is ascertained that Eq. (3) does not lose the validity for the diffusion from the arsenic doped polysilicon. When the molar ratio of $\mathrm{AsCl}_{3} / \mathrm{SiH}_{4}$ is larger than $3.8 \times 10^{-2},{ }^{* 1}$ the total arsenic concentration might exceed a value above the solubility limit, corresponding to the saturations of the sheet resistivity and junction depth.

\subsubsection{Arsenic diffusion coefficient It} has been shown that, in the high-concentration arsenic-diffused-layer obtained by another diffusion technique, the total arsenic concentration $C_{\mathrm{T}}$ is higher than the electrically-active arsenicconcentration $C_{A}{ }^{11), 12), 23)}$. Figure 7 shows profiles of $C_{\mathrm{A}}$ diffused from the doped poly-silicon with

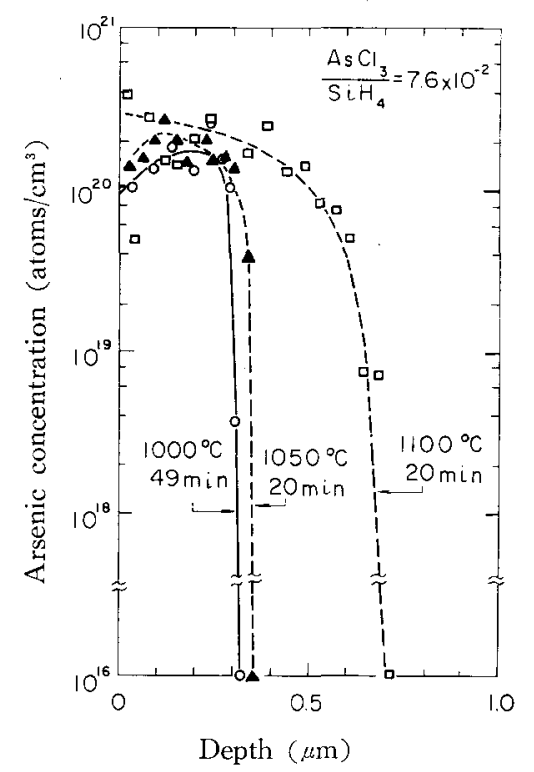

Fig. 7 Diffusion temperature dependence of arsenic concentration profiles obtained with diffusion from arsenic doped poly-silicon with $\mathrm{AsCl}_{3}$ $/ \mathrm{SiH}_{4}$ of $7.6 \times 10^{-2}$

Diffusion conditions are $1000^{\circ} \mathrm{C}, 49$ minutes $(\mathrm{O}), 1050^{\circ} \mathrm{C}, 20$ minutes $(\triangle)$ and $1100^{\circ} \mathrm{C}, 20$ minutes

\footnotetext{
*1 By using atomic absorption spectrophotometry, it becomes clear that the arsenic concentration in the doped poly-silicon (deposited with a molar ratio of $\left.3.8 \times 10^{-2}\right)$ is $7.1 \mathrm{wt} \%$.
} 
$\mathrm{AsCl}_{3} / \mathrm{SiH}_{4}$ of $7.6 \times 10^{-2}$ at 1000,1050 and $1100^{\circ} \mathrm{C}$, respectively. $C_{\mathrm{A}}$ at $1100^{\circ} \mathrm{C}$ is higher than $C_{\mathrm{A}}$ at $1000^{\circ} \mathrm{C}$, i.e. in the doped poly-silicon case, again, $C_{\mathrm{T}}$ is higher than $C_{\mathrm{A}}$ at $1000^{\circ} \mathrm{C} . C_{\mathrm{A}}$ slightly decreases near the surface for the diffusion at $1000^{\circ} \mathrm{C}$ and $1050^{\circ} \mathrm{C}$.

In this paper, $C_{T}$ was calculated by applying Fair's empirical equations ${ }^{24}$ as

$$
\begin{aligned}
& C_{\mathrm{T}}(x)=C_{\mathrm{A}}(x) {[1+\beta(T)] } \\
& \text { for } 0 \leqq x \leqq \frac{1}{2} x_{\mathrm{j}} \\
& C_{\mathrm{T}}(x)=C_{\mathrm{A}}(x) \quad\left[1+\beta(T)\left(C_{\mathrm{A}}(x) / C_{\mathrm{AO}}\right)^{3}\right] \\
& \text { for } \frac{1}{2} x_{\mathrm{j}}<x \leqq x_{\mathrm{j}}
\end{aligned}
$$

where $\beta$ is a fitting parameter and $C_{\mathrm{AO}}$ is the surface concentration of electrically active arsenic. Dotted lines of Fig. 5 A, B, C and D shows the total arsenic profiles corresponding to the solid line profiles shown in Fig. $5 \mathrm{~A}, \mathrm{~B}, \mathrm{C}$ and $\mathrm{D}$ respectively, using $\beta(1000)=2^{24}$.

Figure 8 shows arsenic diffusion coefficients $D_{\text {As }}$ determined by the Boltzmann-Matano analysis as described in Sec. 3.1.3. It should be noted that $D_{\text {As }}$ depends strongly on the total arsenic concentration $C_{\mathrm{T}}$ and is also sensitive to the molar ratio of $\mathrm{AsCl}_{3} / \mathrm{SiH}_{4}$. In addition, $D_{\mathrm{As}}$ has a maximum value at $C_{\mathrm{T}}$ of $2 \sim 4 \times 10^{20}$ $\mathrm{cm}^{-3}$. These values agree with the study reported by Fair $^{11}$ using a doped oxide method.

Table 2 represents $C_{\mathrm{T}} / n_{\mathrm{i}}$ values and $D_{\max } / D_{\mathrm{i}}$ values at $D_{\mathrm{As}}=D_{\max }$ for various ratios of $\mathrm{AsCl}_{3} /$

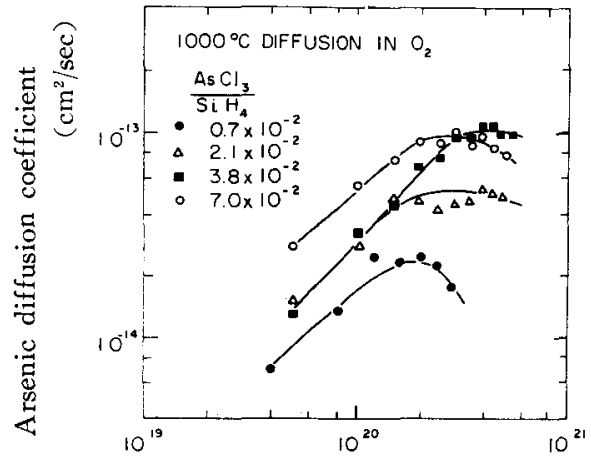

Total arsenic concentration $C_{\mathrm{T}}$ (atoms $/ \mathrm{cm}^{3}$ )

Fig. 8 Relation between arsenic diffusion coefficients and total arsenic concentration

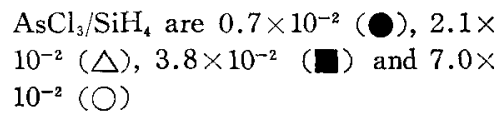

Table 2 Ratios of total to intrinisic arsenic concentrations and ratios of maximum to intrinsic arsenic diffusion coefficient. Diffusion temperature is $1000^{\circ} \mathrm{C}$

\begin{tabular}{c|c|c}
\hline $\mathrm{AsCl}_{3}$ & $\begin{array}{c}C_{\mathrm{T}} \\
n_{\mathrm{i}} \\
\mathrm{SiH}_{4}\end{array}$ & $\frac{D_{\mathrm{max}}}{D_{\mathrm{i}}}$ \\
\hline $0.7 \times 10^{-2}$ & 21 & 12 \\
$2.0 \times 10^{-2}$ & 37 & 27 \\
$3.8 \times 10^{-2}$ & 50 & 52 \\
$7.0 \times 10^{-2}$ & 37 & 50 \\
doped oxide* & 34 & 43 \\
\hline
\end{tabular}

* : After Fair ${ }^{11} C_{\mathrm{TO}}=8.5 \times 10^{20}$ (atoms $/ \mathrm{cm}^{3}$ )

$\mathrm{SiH}_{4}$, where $n_{\mathrm{i}}$ is the intrinisic electron concentration at a given diffusion temperature, $D_{\mathrm{i}}$ is the intrinsic arsenic-diffusion-coefficient at the diffusion temperature and $D_{\max }$ is the maximum value of $D_{\mathrm{As}}$. It indicates that $C_{\mathrm{T}} / n_{\mathrm{i}}$ and $D_{\max } / D_{\mathrm{i}}$ valiues increase as the molar ratio of $\mathrm{AsCl}_{3} / \mathrm{SiH}_{4}$ increases. These values saturate at a molar ratio of larger than $3.8 \times 10^{-2}$.

In the case of doped oxide diffusion, $C_{\mathrm{T}} / n_{\mathrm{i}}$ and $D_{\max } / D_{i}$ at $D_{\mathrm{As}}=D_{\max }$ have been given by ${ }^{11)}$

$$
\begin{aligned}
& \frac{C_{\mathrm{T}}}{n_{\mathrm{i}}}=\frac{0.6 C_{\mathrm{TO}}}{\sqrt{\beta(T)}\{1+\beta(T)\} n_{\mathrm{i}}} \\
& \frac{D_{\max }}{D_{\mathrm{i}}}=\frac{\sqrt[3]{2} C_{\mathrm{TO}}}{3 \sqrt[3]{\beta(T)}|1+\beta(T)| n_{\mathrm{i}}}
\end{aligned}
$$

where $C_{\mathrm{TO}}$ is the surface concentration of total arsenic. If these relations hold in the doped poly-silicon case, the molar ratio dependences of $C_{\mathrm{T}} / n_{\mathrm{i}}$ and $D_{\max } / D_{\mathrm{i}}$ correspond to those of $C_{\text {TO }}$. In the case of molar ratio above $3.8 \times 10^{-2}$, $C_{\mathrm{TO}}$ was approximately $7 \times 10^{20} \mathrm{~cm}^{-3}$, which was nearly equal to that obtained with an arsenic-doped-oxide by Fair ${ }^{11}$.

\subsection{Effect of atmosphere during diffu- sion}

Figure 9 shows the arsenic diffusion profiles obtained with the diffusion in dry $\mathrm{O}_{2}$ and in dry $\mathrm{N}_{2}$ atmospheres. A profile obtained with the diffusion in a dry $\mathrm{O}_{2}$ atmosphere agrees well with that obtained with the diffusion in a dry $\mathrm{N}_{2}$ atmosphere.

As shown in Table 3, the sheet resistivity obtained with diffusion in dry $\mathrm{O}_{2}$ is almost equal to that obtained in dry $\mathrm{N}_{2}$, and the junc- 


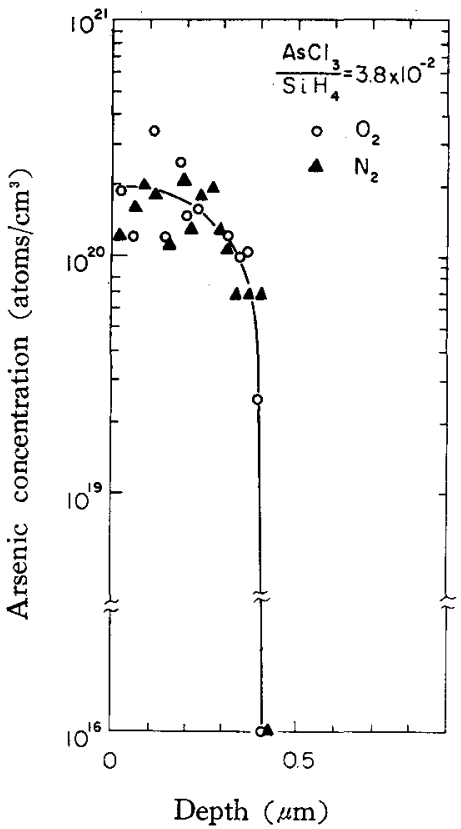

Fig. 9 Arsenic concentration profiles obtained with diffusion in $\mathrm{O}_{2}(\mathrm{O})$ and in $\mathrm{N}_{2}$ (A) at $1000^{\circ} \mathrm{C}$ for 60 minutes

$\mathrm{AsCl}_{3} / \mathrm{SiH}_{4}$ is $3.8 \times 10^{-2}$ and polysilicon thickness is $2500 \AA$

Table 3 Sheet resistivity and junction depth for $1000^{\circ} \mathrm{C}, 60$ minutes diffusion. Molar ratios of $\mathrm{AsCl}_{3} / \mathrm{SiH}_{4}$ and $\mathrm{PH}_{3}$ $/ \mathrm{SiH}_{4}$ are $3.8 \times 10^{-2}$ and $2.6 \times 10^{-2}$, respectively

\begin{tabular}{c|c|c}
\hline \hline $\begin{array}{c}\text { Diffusion } \\
\text { condition }\end{array}$ & $\begin{array}{c}\text { Sheet } \\
\text { resistivity } \\
\rho_{\mathrm{s}}(\Omega / \square)\end{array}$ & $\begin{array}{c}\text { Junction } \\
\text { depth } \mathrm{Xj}(\mu \mathrm{m})\end{array}$ \\
\hline As $1000^{\circ} \mathrm{C}$ & $15\left(\mathrm{O}_{2}\right)$ & $0.48\left(\mathrm{O}_{2}\right)$ \\
$60 \mathrm{~min}$ & $14\left(\mathrm{~N}_{2}\right)$ & $0.45\left(. \mathrm{N}_{2}\right)$ \\
$\mathrm{P} 1000^{\circ} \mathrm{C}$ & $9.6\left(\mathrm{O}_{2}\right)$ & $1.27\left(\mathrm{O}_{2}\right)$ \\
$60 \mathrm{~min}$ & $9.7\left(\mathrm{~N}_{2}\right)$ & $1.16\left(\mathrm{~N}_{2}\right)$ \\
\hline
\end{tabular}

tion depth obtained with diffusion in dry $\mathrm{O}_{2}$ is almost equal to that obtained in dry $\mathrm{N}_{2}$, corresponding to diffusion profiles shown in Fig. 9. In the case of phosphorus doped poly-silicon, the sheet resistivity and the junction depth are almost equal to those obtained in both ambients.

\section{Summary and Conclusion}

Phosphorus and arsenic doped poly-silicon films were prepared from $\mathrm{SiH}_{4}-\mathrm{PH}_{3}-\mathrm{N}_{2}$ and $\mathrm{SiH}_{4}-\mathrm{AsCl}_{3}-\mathrm{N}_{2}$ mixtures, respectively, and then, drive-in diffusions were carried out in dry nitrogen or dry oxygen ambient. Junction depths, sheet resistivities, concentration profiles and diffusion coefficients have been investigated.

Two regions have been observed in the phosphorus profiles, e.g. one region has a diffusion coefficient $D_{\mathrm{I}}$ of $1.2 \times 10^{-14} \mathrm{~cm}^{2} / \mathrm{sec}$ and the other has $D_{\text {II }}$ of $6.0 \times 10^{-14} \mathrm{~cm}^{2} / \mathrm{sec}$ through the diffusion at $900^{\circ} \mathrm{C}$ from doped poly-silicon deposited with the molar ratio $\mathrm{PH}_{3} / \mathrm{SiH}_{4}$ of 2.6 $\times 10^{-2}$. This deviation from a simple complementary error function is qualitatively similar to the cases of doped oxide and conventional gas-phase-diffusion technique.

The arsenic profile diffused from doped polysilicon has also shown a good agreement wit hthe profile from doped-oxide reported by $\mathrm{Fair}^{20)}$. The total arsenic concentration profile determined from the electrically measured profile by means of Fair's method has provided the same diffusion coefficient at $1000^{\circ} \mathrm{C}$ as that of Fair's dopedoxide-diffusion.

Especially, since the phosphorus profile has such a kink point, in comparison with the arsenic profile, only the sheet resistivity measurement on the surface is not enough to control the junction depth. In the case of arsenic diffusion, for constant surface concentration, the junction depth could be controlled by measuring the sheet resistivity.

No remarkable difference has been found between the sheet resistivity and junction depth diffused in both nitrogen and oxygen ambients.

\section{Acknowledgements :}

The authors wish to thank Dr. T. Okada and Dr. $Y$. Haneta for many stimulating discussions and for encouraging this work.

$$
<\text { E436> (Received July } 31,1975 \text { ) }
$$

\section{References :}

1) H. Kamioka, K. Ishii, M. Takagi, FUJITSU Sci. Tech. J. 8, 147 (1972).

2) M.L. Barry, P. Olofsen, J. Electrochem. Soc. 116, 854 (1969).

3) J. Scott, J. Olmstead, RCA REVIEW 26, 357 (1965).

4) J. Wong, M. Ghezzo, J. Electrochem. Soc. 119, 1413 (1972).

5) H. Teshima, Y. Tarui, O. Takeda, Bull. Electrotech. Lab. Japan 33, 631 (1969).

6) T. Abe, K. Sato, M. Konaka, A. Miyazaki, Proc. lst Conf. Solid State Devices. Tokyo, p.88(1969). 
7) K. Nakayama, H. Kamioka, T. Terada, M. Takagi, R. Togei, Electrochem. Soc. Extended Abstracts 72-2 No. 264, p. 652 (1972).

8) B.I. Boltaks, "Diffusion in Semiconductors", p. 124 (1963), Academic Press, New York.

9) J. C. C. Tsai, Proc. of IEEE 57, 1499 (1969).

10) M. Yoshida, E. Arai, H. Nakamura, Y. Terunuma, J. Appl. Phys. 45, 1498 (1974).

11) R.B. Fair, G.R. Weber, ibid. 44, 273 (1973).

12) F.C. Eversteyn, B.H. Put, f. Electrochem. Soc. 120, 106 (1973).

13) J.C. Irvin, Bell. Syst. Tech. J. 41, 387 (1962).

14) M.E. Cowher, T.O. Sedgwick, J. Electrochem. Soc. 119, 1565 (1972).

15) E. Tannenbaum, Solid-State Electron 2, 123 (1961).
16) M.C. Duffy, F. Barson, J.M. Fairfield, G.H. Schwuttke, J. Electrochem. Soc. 115, 84 (1968).

17) S. Prussin, J. Appl. Phys. 32, 1876 (1961).

18) Y. Yasuda, T. Moriya, Electrochem. Soc. Meeting Symposium (Paper 271, May 1973).

19) Y. Nakajima, S. Ohkawa, Y. Furukawa, Japan J. Appl. Phys. 10, 162 (1971).

20) R.B. Fair, J. Electrochem. Soc. 119, 1389 (1972).

21) R.B. Fair, J. Appl. Phys. 43, 1278 (1972).

22) T.L. Chiu, H.N. Ghosh, IBM. J. Res. Develop. 15, 477 (1971).

23) S. Ohkawa, Y. Nakajima, T. Sakurai, H. Nishi, Y. Furukawa, Japan J. Appl. Phys. 13, 361 (1974).

24) R.B. Fair, J. Appl. Phys. 44, 280 (1973). 